\title{
ANALISIS MISKONSEPSI GURU MATEMATIKA JENJANG SMA PADA MATERI NILAI MUTLAK
}

\author{
Analyzing the Misconceptions of Senior High School Mathematics Teacher \\ on Absolute Value
}

\author{
${ }^{1 *)}$ Mahmun Zulkifli, ${ }^{2 *}$ Sumardyono \\ ${ }^{1}$ PPPPTK MatematikaJl. Kaliurang km. 6, DI. Yogyakarta, Telp (0274) 274885752, Kode Pos 55283, \\ Indonesia \\ ${ }^{2}$ PPPPTK Matematika Jl. Kaliurang km. 6, DI. Yogyakarta, Telp (0274) 274885752, Kode Pos 55283, \\ Indonesia \\ *) mahmun.zulkifli@kemdikbud.go.id
}

\begin{abstract}
Misconceptions are common in mathematics and happen not only in students but also in teachers. This situation must be minimized so that mathematics learning can run appropriately. Therefore, this study aims to analyze the misconceptions of high school mathematics teachers on the subject of absolute value. The research was conducted at the Mathematics Teacher Organization of the Special Province of Yogyakarta. The subjects of this study consisted of 123 high school mathematics teachers. The instrument consists of written tests and interviews. The method used in this research is a descriptive qualitative method. The results obtained showed that there are two types of teachers' misconceptions on the subject of absolute value. First, there is a misconception about understanding the concept of absolute fundamental value by $46 \%$, which includes being unable to distinguish between the idea of absolute value and absolute-value equation. Secondly, there is a misconception in resolving absolute-value inequalities by $16.6 \%$ including mistakes on the concept of distance on absolute-value inequalities and misconceptions on the concept of quadratic inequalities
\end{abstract}

Keywords :absolute-value equation, absolute-value inequalities, misconceptions of senior high school mathematics teacher, descriptive qualitative

\begin{abstract}
ABSTRAK
Kesalahan konsep (miskonsepsi) merupakan hal yang jamak terjadi dalam pelajaran matematika dan terjadi tidak hanya pada siswa melainkan juga terjadi pada guru. Situasi ini harus diminimalisir agar pembelajaran matematika dapat berlangsung dengan baik. Oleh karena itu, penelitian ini bertujuanuntuk menganalisis miskonsepsi yang terjadi pada guru matematika jenjang SMA pada materi nilai mutlak. Penelitian dilakukan di Musyawarah Guru Mata Pelajaran (MGMP) Matematika Provinsi Daerah Istimewa Yogyakarta. Subjek penelitian ini terdiri dari 123 guru mata pelajaran matematika jenjang SMA. Instrumen terdiri dari tes tertulis dan wawancara. Metode yang digunakan dalam penelitian ini adalah metode diskriptif kualitatif. Hasil penelitian yang diperoleh menunjukkan bahwa terdapat 2 tipe miskonsepsi guru pada materi nilai mutlak. Pertama, adanya miskonsepsi tentang pemahaman konsep nilai dasar mutlak sebesar $46 \%$ yang meliputi menjadi ketidakmampuan membedakan antara konsep nilai mutlak dengan persamaan nilai mutlak. Kedua, adanya miskonsepsi dalam menyelesaikan pertidaksamaan nilai mutlak sebesar $16,6 \%$ yang meliputi miskonsepsi pada konsep jarak pada pertidaksamaan nilai mutlak dan miskonsepsi pada konsep pertidaksamaan kuadrat.
\end{abstract}

Kata Kunci: diskriptif kualitatif, miskonsepsi guru matematika SMA, persamaan nilai mutlak, pertidaksamaan nilai mutlak. 


\section{PENDAHULUAN}

Mata pelajaran matematika merupakan mata pelajaran wajib bagi seluruh siswa mulai dari jenjang SD hingga jenjang SMA/sederajat. Untuk itu keberadaan guru sangat penting untuk menanamkan konsep yang tepat pada mata pelajaran ini. Sejalan dengan itu tujuan yang ingin dicapai oleh pendidikan matematika dapat diklasifikasikan menjadi (1) tujuan yang bersifat formal dan, (2) tujuan yang bersifat material. Tujuan yang bersifat formal lebih menekankan kepada menata penalaran dan membentuk kepribadian, sedang tujuan yang bersifat material lebih menekankan kepada kemampuan menerapkan matematika dan keterampilan matematika. Baik tujuan formal maupun tujuan material, akan sulit dicapai bila isi (content) matematika itu sendiri tidak dikuasai dengan benar. (Soedjadi, 2000;45)

Miskonsepsi matematika (mathematics misconception) termasuk apa yang disebut dengan istilah "kesalahan matematika" (mathematical errors). Kesalahan ini meliputi pengertian yang tidak akurat tentang konsep, penggunaan konsep yang salah, klasifikasi contoh-contoh yang salah, kekacauan konsep-konsep yang berbeda, dan hubungan hierarkis konsep-konsep yang tidak benar (Fortuna R, Edy, \& Gloria, 2013:3). Bila hal tersebut terjadi pada siswa maka kemajuan belajar siswa dalam literasi matematika akan terhambat, karena siswa tidak memiliki kemampuan dalam menggunakan konsep-konsep matematika untukmengelola informasi yang ada. Terlebih lagi ketidakmampuan memahami konsep-konsep matematika akan berakibat pada kesulitan memahami konsep yang lebih kompleks atau topik lebih lanjut. Konsep-konsep matematika tersusun secara hirarkis, satu konsep menjadi dasar bagi konsep lainnya. Sementara itu bila kesalahan konsep matematika itu terjadi pada guru, maka dapatberakibat lebih fatal lagi, karena akan mewariskan kesalahan konsep pada anak didiknya.

Sudah cukup banyak penelitian miskonsepsi matematika pada siswa yang dilakukan, namun belum banyak penelitian miskonsepsi matematika yang terjadi pada guru. Miskonsepsi matematika yang terjadi pada siswa dapat saja dipengaruhi oleh apa yang diajarkan oleh guru dan bagaimana cara guru mengajar. Oleh karena itu, diperlukan usaha untuk selalu meningkatkan kompetensi profesional guru, tidak terkecuali kompetensi pedagogik dalam mengajar matematika. Untuk itu, penelitian ini bermaksud untuk mengekplorasi miskonsepsi yang terjadi pada guru terutama pada materi niai mutlak, agar para guru memperoleh informasi mengenai apa yang terjadi dan dapat mengantisipasinya dalam pembelajaran. Bagi lembaga, penelitian ini menjadi input untuk penyelenggaraan program fasilitasi peningkatan kompetensi guru matematika secara lebih efektif.

Materi nilai mutlak merupakan salah satu materi pada mata pelajaran Matematika. Beberapa penelitian tentang kesalahan dalam menyelesaikan permasalahan matematika diantaranya adalah pemahaman mahasiswa calon guru matematika dalam menyelesaikan masalah ketaksamaan nilai mutlak, kemampuan memahami konsep nilai mutlak, memahami sifat-sifat ketaksamaan nilai mutlak, dan prosedur dalam menyelesaikan masalah ketaksamaan nilai mutlak (Usman, 2015: 21). Kesalahan dalam menyelesaikan nilai mutlak akan berdampak pada kesalahan siswa dalam menyelesaiakan masalah yang sama. Penelitian menemukan bahwa faktor penyebab kesalahan dalam menyelesaikan permasalahan nilai mutlak satu variabel adalah kesalahan konsep dan kesalahan operasi (Saktiawan, 2019:339). Oleh karena itu peneliti sebagai pengajar merasa tertarik untuk menganalisis miskonsepsi yang terjadi pada guru Matematika jenjang SMA pada materi nilai mutlak.

\section{METODE}

Metode penelitian bersifat deskriptif kualitatif bertujuan untuk menganalisis miskonsepsi yang terjadi pada guru matematika jenjang SMA pada materi Nilai Mutlak.Deskripsidiperlukan untuk menjelaskan ruang lingkup dan kedalaman miskonsepsi yang dialami guru, termasuk faktor penyebab yang menjadi dugaan terjadinya miskonsepsi. Penelitian ini bersifat kualitatif karena lebih difokuskan pada kualifikasi miskonsepsi yang terjadi, sementara kuantifikasi hanya sebagai analisis 
tambahan yang mendukung saja. Penelitian ini dilaksanakan di MGMP Matematika SMA ProvinsDaerah IstimewaYogyakarta. Subjek penelitian ini terdiri dari 123 guru mata pelajaran matematika jenjang SMA. Instrumen terdiri dari tes tertulis dan wawancara. Tes diperlukan untuk mendapatkan informasi langsung mengenai miskonsepsi yang mungkin dialami para guru matematika. Tes bersifat terbuka yaitu jawaban yang dikehendaki muncul dari responden sepenuhnya diserahkan pada responden itu sendiri. Pertanyaan yang diajukan fokus pada dugaan miskonsepsi yang mungkin dialami para guru berdasarkan kajian teori dan hasil-hasil penelitian sebelumnya. Berdasarkan potensi miskonsepsi yang mungkin terjadi, disusun instrumen berupa panduan wawancara yang sesuai untuk menggali informasi yang lebih mendalam, mengapa suatu miskonsepsi terjadi pada tes yang telah diberikan. Wawancara dilakukan pada beberapa responden yang terpilih dari hasil tes dengan miskonsepsi yang terbanyak, agar mendapat informasi yang lebih beragam

\section{HASIL DAN PEMBAHASAN}

\section{Miskonsepsi yang berhubungan dengandefinisi nilaimutlak}

Pada bagian ini peserta diminta untuk mendefinisikan bentuk nilai mutlak $|2 x-1|$. Tujuan soal ini adalah untuk melihat kemampuan pemahaman responden tentang definisi fungsi nilai mutlak. Kemampuan ini merupakan kemampuan dasar bagi guru untuk memahami konsep-konsep lanjutan dari nilai mutlak.

Nilai mutlak suatu bilangan real $x$, dinyatakan dengan $|\mathrm{x}|$, didefinisikan sebagai

$$
|x|=\left\{\begin{array}{c}
x \text { jika } x \geq 0 \\
-x \text { jika } x<0
\end{array}\right.
$$

Berdasarkan definisi nilai mutlak di atas, maka seharusnya jawaban responden adalah

$$
|2 x-1|= \begin{cases}2 x-1 & \text { jika }(2 x-1) \geq 0 \\ 1-2 x & \text { jika }(2 x-1)<0\end{cases}
$$

Berikut tabulasi hasil pengerjaan menguraikan bentuk nilai mutlak menggunakan definisi nilai mutlak. Dari 123 guru diperoleh data sebagai berikut.

Tabel 1. Kategori jawaban responden masalah 1

\begin{tabular}{lc}
\hline Kategori Responden & Jumlah \\
\hline Responden Menjawab & 116 \\
Responden Menjawab Benar & 60 \\
Responden tidak Menjawab & 7 \\
Miskonsepsi & 56 \\
\hline
\end{tabular}

Jawaban peserta ternyata sangat beragam, dari responden yang berjumlah 123 orang, 116 orang menjawab soal yang berkaitan dengan definisi nilai mutlak ada 7 orang responden tidak menjawab. Ada 60 (49\%) orang yang menjawab benar. Ada 56 (46\%) orang yang diidentifikasi miskonsepsi tentang definisi nilai mutlak. Hasil pengelompokkan dari 56 orang yang teridentifkasi miskonsepsi dapat dikategorikan menjadi 2 bagian besar yaitu;

a. Miskonsepsi yang paling banyak dilakukan oleh responden adalah menyelesaikan soal di atas dengan menjadikannya ke dalam bentuk persamaan linear. Miskonsepsi ini terjadi pada 39 orang responden atau setara dengan 69,6\% dari responden yang terdeteksi melakukan miskonsepsi. Kesalahan ini dilakukan karena konsep dasar nilai mutlak tidak dipahami oleh responden. Responden tidak memahami dengan benar definisi nilai mutlak dan bagaimana cara menjabarkan bentuknilai mutlak sesuai dengan konsep yang benar.Kesalahan ini terjadi karena ketidakcermatan responden. Ketidakcermatan terjadi karena tidak menguasai konsep dengan benar.Hal ini mudah dipahami karena pikiran responden masih terpola perhitungan bukan 
konsep.Responden menggunakan prosedur yang tidak tepat (inapproriate procedure) dalam menjawab soal yaitu responden menggunakan prinsip/rumus secara tidak tepat.Hal ini dapat sejalan dengan penelitian yang dilakukan oleh Gilmore yang menyatakan bahwa memecahkan masalah matematika memerlukan keseimbangan pengetahuan konseptual dan keterampilan prosedural(Gilmore dkk, 2017:410).Pengetahuan konseptual melibatkan pemahaman tentang prinsip-prinsip dan hubungan, sementara keterampilan prosedural melibatkan kemampuan untuk melakukan urutan operasi secara efektif.

Berikut contoh pengerjaan responden.

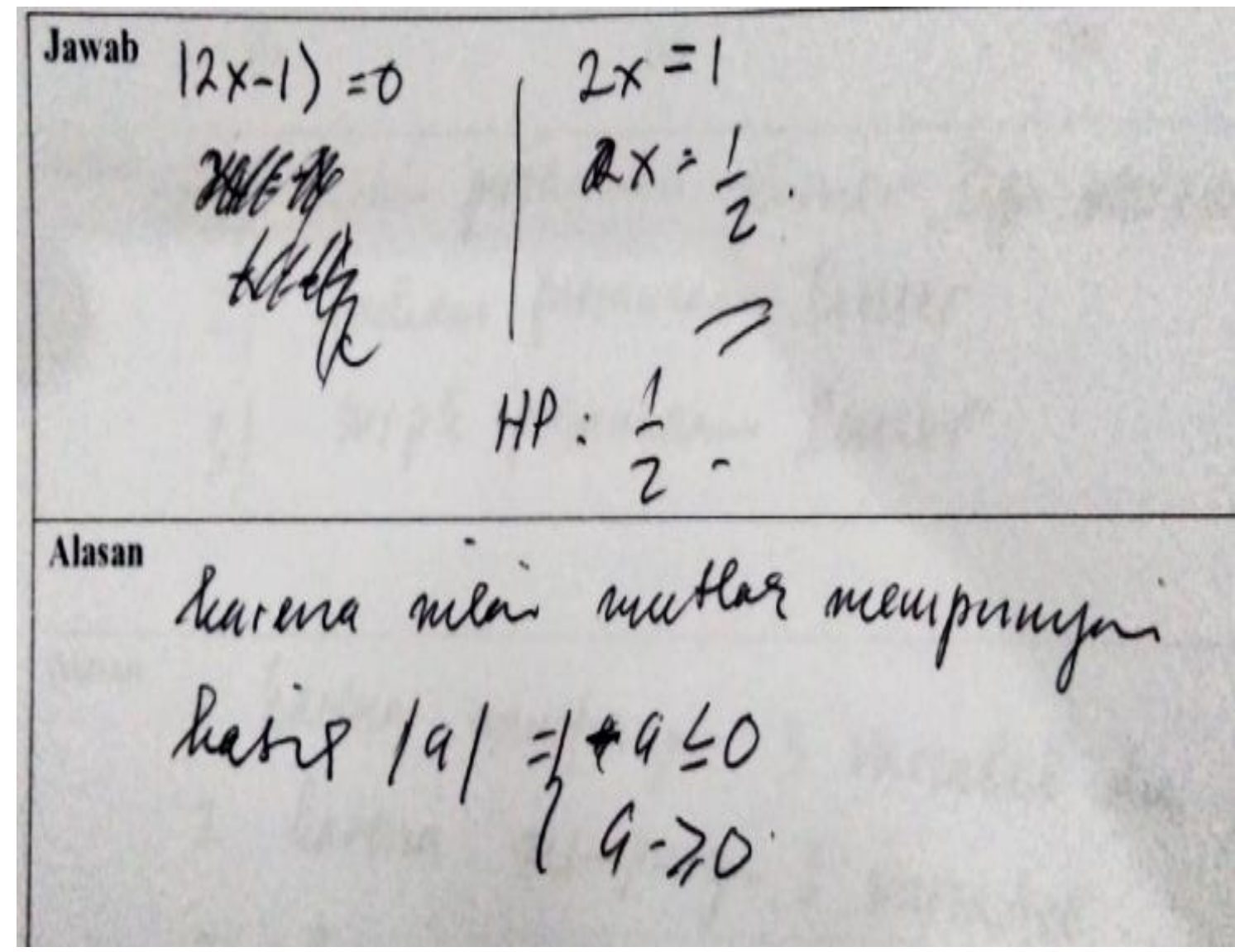

Gambar 1. Jawaban Responden (1)

b. Miskonsepsi kedua yang banyak dijumpai adalah responden menjawab konsep nilai mutlak dengan menjadikannya menjadi pertidaksamaan.Miskonsepsi ini terjadi pada 17 responden atau setara dengan 30,4\% dari responden yang terdeteksi melakukan miskonsepsi. Pada kasus ini responden menjawab dengan caranya sendiri. Responden menjawab dengan mengubah bentuk $|2 x-1|$ menjadi bentuk pertidaksamaan $-1 \leq 2 x-1 \leq 1$.

Mencermati jawaban dari responden dapat disimpulkan bahwa responden tidak mengetahui konsep nilai mutlak. Melihat jawaban responden, terlihat bahwa responden dipengaruhi oleh konsep pertidaksamaan nilai mutlak. Pertidaksamaan nilai mutlak yang mempengaruhi responden adalah "jika $|x|<a$, maka $-a<x<a$, dimana $a \geq 0$ ". 


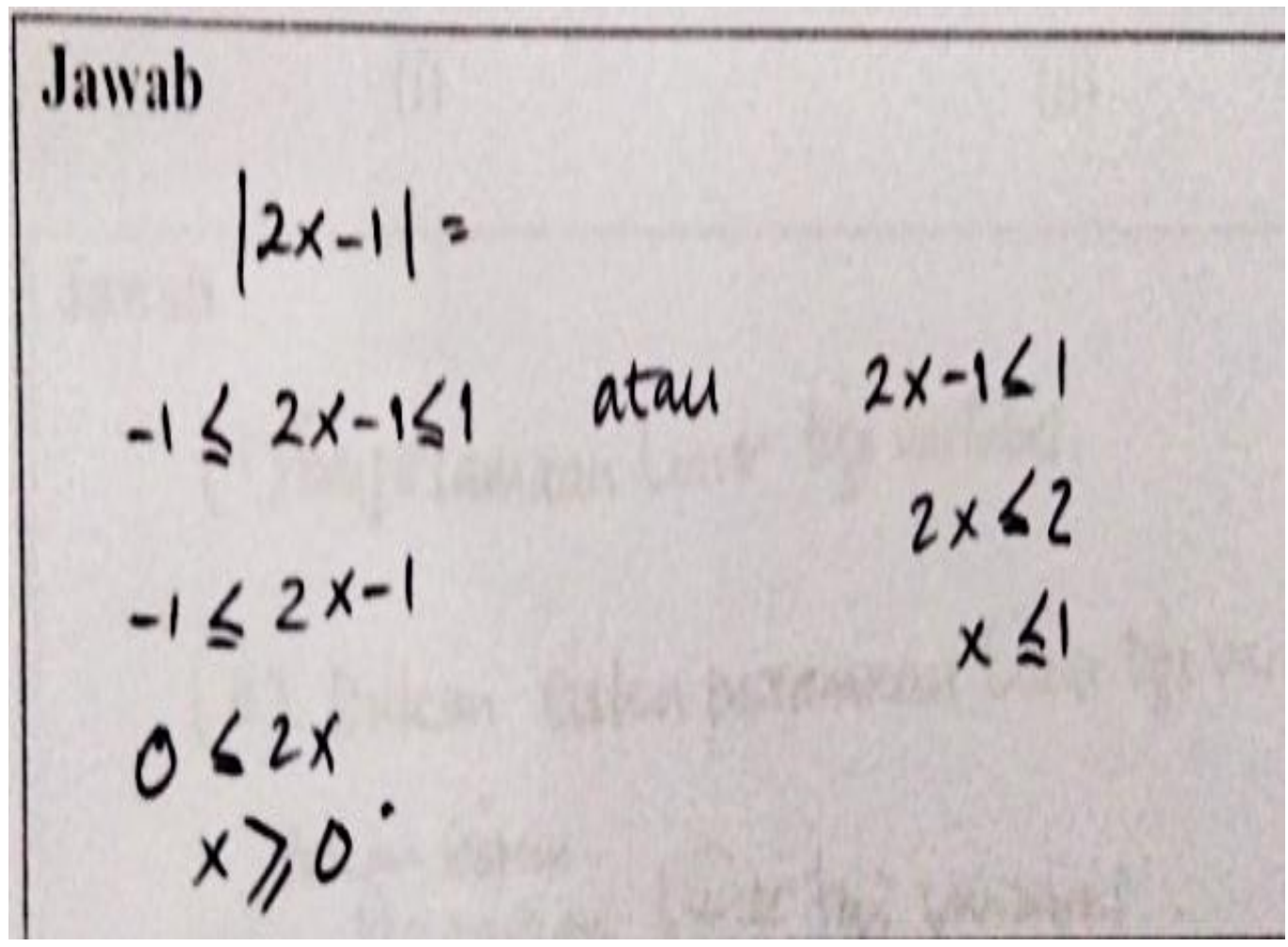

Gambar 2. Jawaban Responden (2)

Berdasarkan hasil wawancara terhadap responden untuk mengetahui penyebab miskonsepsi adalah beberapa responden memang terjebak dengan perhitungan penyelesaian nilai mutlak, dengan menggunakan rumus. Mereka tidak terbiasa menyatakan definisi dengan beragam bentuk dan cara pada nilai mutlak.Hal ini sejalan dengan penelitian yang dilakukan oleh Tian Abdul Aziz, dkk (Aziz, 2019:203) bahwa pemahaman akan definisi nilai mutlak tidak konsisten, menghapus tanda nilai mutlak, memfokuskan hanya pada rumus dan mengubah tanda nilai mutlak menjadi tanda kurung.

Hasil wawancara juga mengungkap bahwa sebagian responden mengakubuku pendukung dalam pembelajaran di SMA tidak membahas tentang teori nilai mutlak secara lengkap. Kekurangan referensi ini hampir dirasakan semua responden yang mengalami miskonsepsi akan materi ini. Kurangnya referensi disebabkan karena materi nilai mutlak terdapat pada Mata Pelajaran Matematika Peminatan Kelas X. Matematika Peminatan di SMA buku referensi baik Buku Siswa maupun Buku Guru tidak disediakan oleh Kementerian Pendidikan melainkan oleh penerbit buku swasta.Sebagian lagi menyatakan bahwa materi nilai mutlak sudah lama tidak mereka ajarkan karena mengajar hanya di kelas XI (nilai mutlak dipelajari di kelas X). Jadi salah satu kemampuan guru dipengaruhi oleh aktivitas pembelajaran yang dilakukan oleh guru itu. 


\section{Miskonsepsi dalam menyelesaikan pertidaksamaan nilai mutlak}

Pada bagian ini peserta diminta untuk menyelesaikan pertidaksamaan $|2 x-3| \leq 1$. Soal ini untuk melihat kemampuan responden tentang konsep pertidaksamaan nilai mutlak. Kemampuan ini merupakan pemahaman berikutnya dari konsep nilai mutlak. Menyelesaikan pertidaksamaan nilai mutlak responden harus menguasai konsep jarak. Pertaksamaan $|x|<a$, artinya jarak dari titik $x$ ke titik 0 kurang dari $a$. Pertaksamaan $|x|<a$ dapat digambarkan dengan garis bilangan berikut.

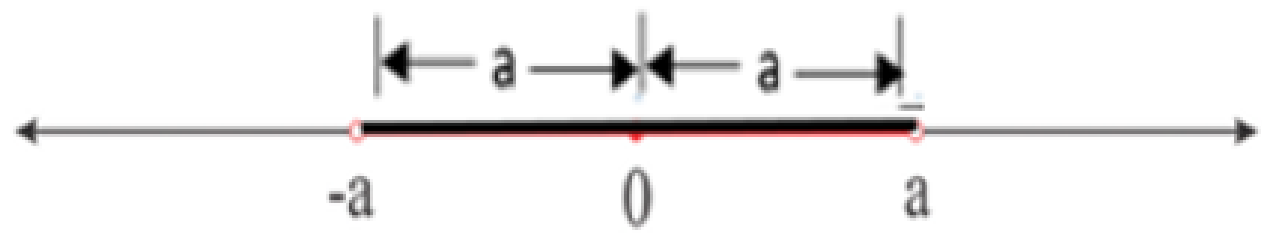

Pertaksamaan $|x|>a$ artinya jarak dari titik $x$ ke titik 0 lebih dari $a$. Pertaksamaan $|x|>a$ dapat digambarkan dalam garis bilangan berikut;

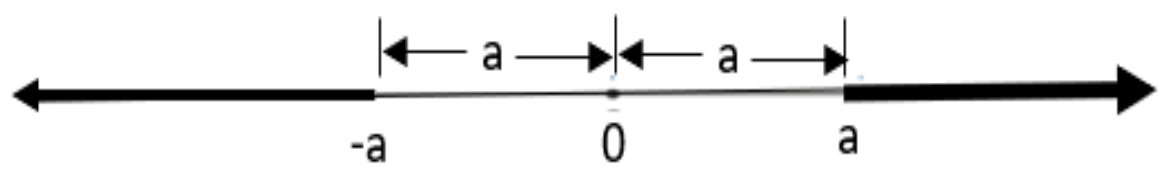

Berdasarkan jawaban responden dari 123 guru diperoleh data sebagai berikut.

Tabel 2. Kategori jawaban responden masalah 2

\begin{tabular}{ll}
\hline Kategori Responden & Jumlah \\
\hline Responden Menjawab & 120 \\
Responden Menjawab Benar & 107 \\
Responden tidak Menjawab & 3 \\
Miskonsepsi & 13 \\
\hline
\end{tabular}

Responden yang menjawab adalah 120 responden dari 123 responden $(97,6 \%)$, kemudian yang menjawab benar adalah 107 responden (87\%), responden yang menjawab salah adalah 13 orang $(10,6 \%)$.

Data di atas menunjukkan bahwa miskonsepsi dalam menyelesaikan pertidaksamaan nilai mutlak ada $10,6 \%$. Secara umum responden memahami dengan baik konsep pertidaksamaan nilai mutlak. Responden yang terindikasi miskonsepsi tidak menjawab masalah ini dengan konsep jarak seperti uraian di atas. Jika diselesaikan dengan konsep jarak pada nilai mutlak akan sangat mudah diselesaikan. Pada kasus ini responden yang menguasai konsep dengan baik akan menyelesaikan masalah ini dengan konsep jarak pada nilai mutlak. Jika responden menyelesaiakan dengan konsep jarak pada nilai mutlak maka jawaban dari $|2 x-3| \leq 1$ adalah $-1 \leq|2 x-3| \leq 1$ dan disederhanakan menjadi $1 \leq x \leq 2$.

Sebanyak 87 responden sudah menjawab sesuai dengan konsep jarak, sedangkan peserta yang terindikasi mengalami miskonsepsi ada 13 orang.

Hasil pengelompokkan dari 13 orang yang teridentifkasi miskonsepsi dapat dikategorikan menjadi 3 bagian besar yaitu; 
a. Miskonsepsi yang ditemui pada masalah ini seperti gambar berikut;

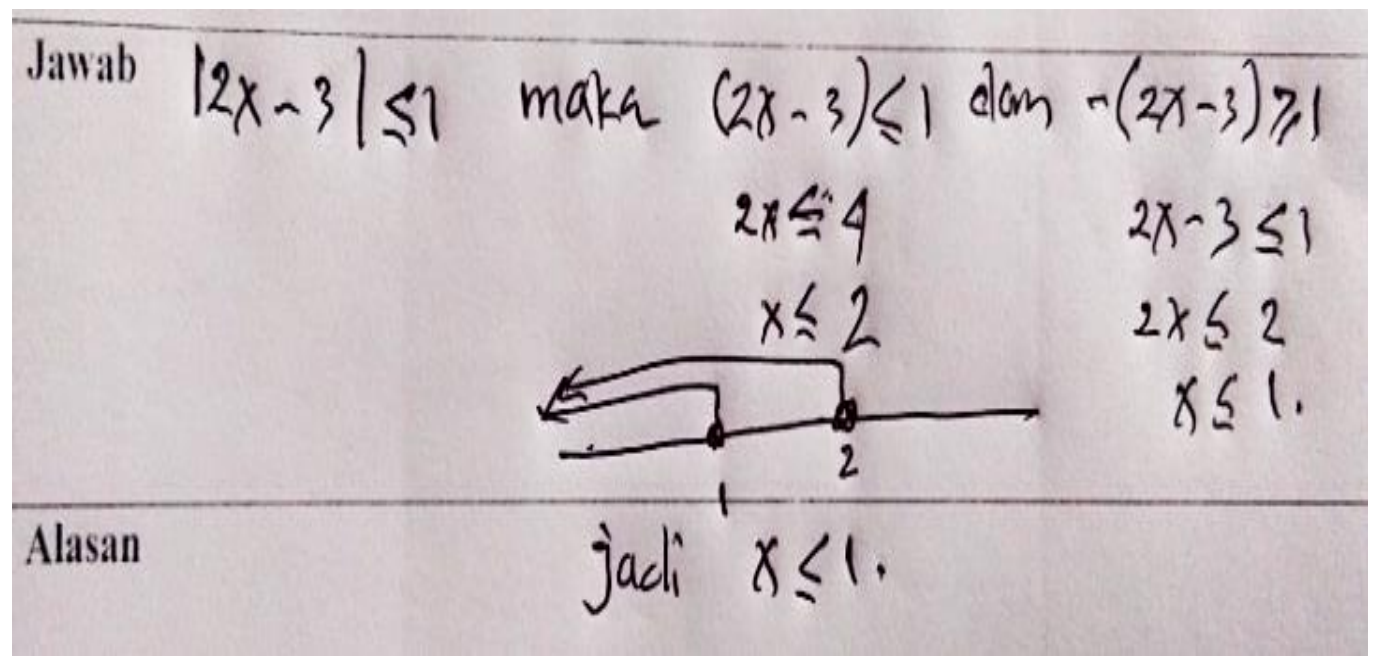

Gambar 3. Jawaban Responden (3)

Jawaban pada gambar di atas responden menjawab sesuai dengan konsep nilai mutlak yaitu

$|x|=\left\{\begin{array}{c}x \text { jika } x \geq 0 \\ -x \text { jika } x<0\end{array}\right.$

Responden tidak memahami dengan benar konsep pertidaksamaan nilai mutlak. Miskonsepsi terdapat pada satu orang responden. Berdasarkan hasil wawancara terhadap responden dengan miskonsepsi ini terungkap bahwa responden dipengaruhi oleh definisi nilai mutlak, sehingga responden menjawab seperti definisi nilai mutlak. Responden dengan miskonsepsi ini ternyata menjawab dengan benar pada soal pertama.

b. Miskonsepsi berikutnya dapat diwakili oleh gambar berikut;

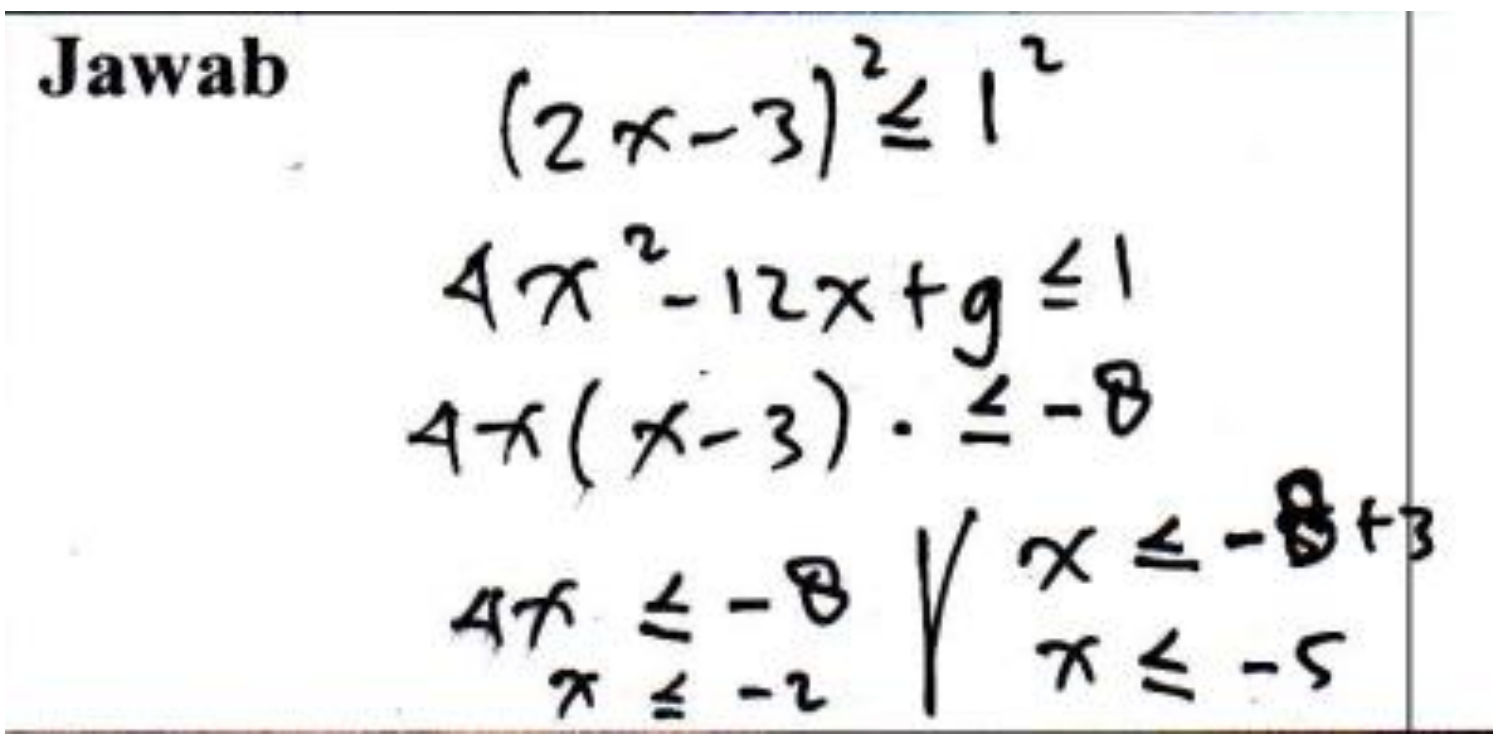

Gambar 4. Jawaban Responden (4)

Berdasarkan jawaban pada gambar di atas responden menjawab tidak menggunakan konsep jarak melainkan menggunakan sifat-sifat nilai mutlak yaitu $|x| \leq|y| \leftrightarrow x^{2} \leq y^{2}$. Penggunaan sifat-sifat dari nilai mutlak $|x| \leq|y| \leftrightarrow x^{2} \leq y^{2}$ dapat digunakan untuk menjawab 
permasalahan di atas, asalkan prosedur dan langkah-langkahnya tepat. Pada jawaban di atas responden melakukan kesalahan pada baris ke-3. Kesalahan yang dilakukan adalah dalam menyederhanakan bentuk pertidaksamaan,dengan demikian responden miskonsepsi yang dilakukan oleh responden adalah pada menyederhanakan bentuk aljabar dari pertidaksamaan. Miskonsepsi pada kasus adalah miskonsepsi pada konsep pertidaksamaan khususnya pertidaksamaan kuadrat.Miskonsepsi pada konsep pertidaksamaan kuadrat terdapat pada 8 orang responden.

Berdasarkan wawancara terhadap 8 responden yang menggunakan sifat nilai mutlak $|x| \leq|y| \leftrightarrow$ $x^{2} \leq y^{2}$ dalam menjawab pertidaksamaan nilai mutlak terungkap bahwa responden sudah terbiasa menyelesaikan soal pertidaksaman nilai mutlak menggunakan sifat $|x| \leq|y| \leftrightarrow x^{2} \leq$ $y^{2}$ karena lebih mudah diingat dan lebih mudah diselesaikan.

c. Miskonsepsi berikutnya pada menyelesaikan pertidaksamaan nilai mutlak adalah kesalahan dalam melakukan perhitungan.Kesalahan ini terdapat pada 4 orang responden.Kesalahan ini mencakup kesalahan melakukan pembagian dan kesalahan dalam melakukan penjumlahan. Kesalahan perhitungan dapat dilihat pada gambar berikut;

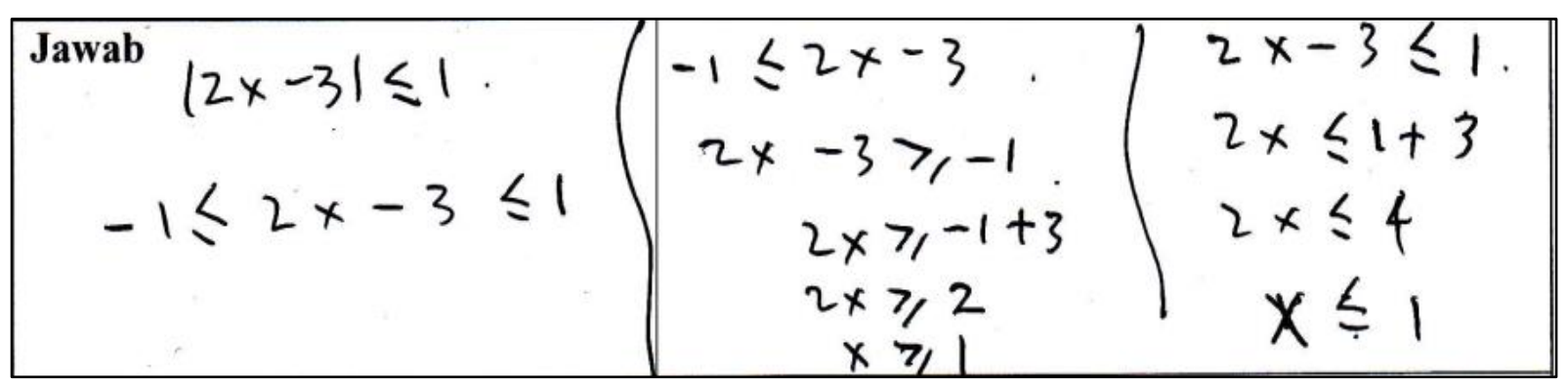

Gambar 5. Jawaban Responden (5)

Berdasarkan jawaban dari gambar di atas responden sudah memahami dengan benar konsep pertidaksamaan nilai mutlak tetapi kurang teliti dalam melakukan operasi hitung.

\section{SIMPULAN DAN SARAN}

Berdasarkan pembahasan hasil penelitian dapat disimpulkan bahwa terdapat miskonsepsi guru pada penguasaan materi nilai mutlaksebagai berikut;

1) Miskonsepsi pada pemahaman konsep nilai mutlak sebesar $46 \%$ dari seluruh responden yang dibedakan menjadi tidak dapat membedakan antara konsep nilai mutlak dengan persamaan nilai mutlak terjadi pada $32 \%$ dari seluruh responden dan miskonsepsi pada penyelesaian pertidaksamaan nilai nilai mutlak sebesar $14 \%$ dari seluruh responden.

2) Miskonsepsi pada konsep pertidaksamaan nilai mutlak sebesar $16,6 \%$ dari seluruh responden. Miskonsepsi ini meliputi miskonsepsi pada konsep jarak pada pertidaksamaan nilai mutlak, miskonsepsi pada konsep pertidaksamaan kuadrat, dan kesalahan perhitungan.

Berdasarkan kesimpulan di atas, maka saran yang dapat disampaikan adalah.

1) Perlunya guru mere-evaluasi pengetahuan dan pemahaman tentang konsep nilai mutlak.

2) Perlunya pemahaman yang utuh tentang konsep nilai mutlak.

3) MGMP Matematika Provinsi DIY dapat melakukan pengembangan kompetensi profesional terhadap materidiMGMP wilayah kerjanya masing-masing. 


\section{UCAPAN TERIMA KASIH}

Terima kasih peneliti ucapkan kepada PPPPTK Matematika yang telah memfasiltasi penelitian melalui kegiatan Risetmatika baik berupa dana dan kebijakan sehingga penelitian ini dapat berlangsung dengan baik. Terima kasih kepada Kepala PPPPTK Matematika periode yang lalu Ibu Dr. Dra. Daswatia Astuty, M.Pd yang telah memberikan kepercayaan kepada peneliti untuk melakukan penelitian ini. Terima kasih juga kepada rekan-rekan panitia Risetmatika dengan bekerja keras sehingga kegiatan Risetmatika dapat berlangsung dengan baik.

\section{DAFTAR PUSTAKA}

Aziz, T. A., Supit, \& Soenarto, Y. (2019). Pre-Service Secondary Mathematics Teachers' Understanding of Absolute Value. Cakrawala Pendidikan, Vol. 38, 203 - 214. doi:10.21831/cp.v38i1.21945

Fortuna R, D., Edy, C., \& Gloria, R. Y. (2013). Pengembangan Tes DIagnostik Untuk Mengukur Miskonsepsi Siswa pada Pokok Bahasan Sistem Regulasi Manusia Untuk Siswa Kelas XI Semester II. Scientiae Educatia: Jurnal Pendidikan Sains, 1 - 18.

Gilmore, C., Keeble, S., Richardson, S., \& Cragg, L. (2017). The Interaction of Procedural Skill, Conceptual Understanding and Working Memory in Early Mathematics Achievement. Journal of Numerical Cognition, 400-416.

Saktiawan, O., Maulidiya, D., \& Siagian, T. (2019). Jenis Kesalahan Siswa dalam Menyelesaikan Soal Persamaan Nilai Mutlak Linear Satu Variabel. Jurnal Penelitian Pembelajaran Matematika Sekolah (JP2MS), Vol 3, 393-401.

Soedjadi, R. (2000). Kiat Pendidikan Matematika di Indonesia: Konstatasi Keadaan masa Kini Menuju Harapan Masa Depan. Jakarta: Direktorat Jenderal Pendidikan Tinggi.

Usman, Hasbi, M., \& Bambang, R. (2015). Pemahaman Siswa Calon Guru Matematika dalam Menyelesaikan Masalah Ketaksamaan Nilai Mutlak. Jurnal Peluang, Vol. 3, 13 - 23. 